gland is either an organ which was formerly of use and is now passing away, or that it is connected 'with some unknown process of nutrition.' That its activity 'is decidedly connected with the growth of young fronds' stands in favor of the latter view. A supplementary suggestion has already been made by the writer to the effect that the solution of actively secreted sugar may act as a carrier for some other substance in the nature of an excretion.*

The writer has observed on the surface of the gland in some cases a felt of darkcolored fungal hyphae. The occurrence of these, when the leaf-blade has not yet unfolded, carries with it the suggestion that the nectarial surface is a constant infectionpoint, the sugary fluid acting as a nutrient medium and the entrance of the hyphae being made easy by the large stomata.

\section{ORIGIN OF THE NECTARY.}

Certain facts which have bèn pointed out give us grounds for offering a view of the origin of the nectaries, to the effect that they have arisen as portions of the respiratory areas of the petiole and its branches, which have become secondarily specialized as nectar-secreting glands.

In support of this view, we recall the relation of the nectaries to the stomatal bands (pneumathodes), with which they have a practically identical structure, with, however, a more intimate connection with the vascular system. We regard the wide distribution of these band-shaped pneumathode regions in the ferns as indicating a phylogenetically greater age than that of the nectaries as such. If this be true, Francis Darwin's suggestion, quoted above, that the nectary is an organ once useful but now on the wane, must probably be thrown out of court, though not necessarily. Further, the stomata, while clearly func-

\footnotetext{
* Bonnier (l.c.) has shown that other"substances are thrown off in small quantities.
}

tionless as pneumathodes during the period of the gland's activity, and deprived of the delicate mechanisms for closure both by their own development and the manner of growth of the surrounding epidermis, are nevertheless to be regarded as respiratory mechanisms, serving the function of setting free the nectar. The analogous conditions in Tropaeolum and other plants may be cited as a parallel case save in the nature of the exudate. The presence of the substomatic spaces, usually broader beneath the stoma than represented in Fig. 3, together with the intercellular spaces both suggest the same thing.

It is to be questioned if the presence of chlorophyll in the gland has any necessary relation to the activity of the organ as a gland, upon which point further study of the cytological phenomena may throw light.

Haberlandt* has drawn the provisional conclusion with regard to nectaries in general, that they have been derived phylogenetically from hydathodes. In summarizing the present paper we submit the case described herewith as one in which the nectaries have been derived both ontogenetically and phylogenetically from pneumathodes.

\section{Teachers College, Columbia University. \\ Francis E. Lloyd. \\ THE BRITISH NATIONAL ANTARCTIC EXPEDITION.†}

The resignation of the man who is, before all others, fitted to be the Scientific Leader of the National Antarctic Expedition will lead the fellows of the Society to expect some statement of the causes which have produced a result so disastrous to the interests of science. The following statement gives an account of the efforts which

* 'Physiologische Pflanzenanatomie,' p. 432.

$\uparrow$ A letter addressed by Professor Edward B. Poulton, of Oxford University, to the fellows of the Royal Society. 
have been made to prevent the injury which has occurred.

In the autumn of 1899, Captain Tizard, F.R.S., and I were appointed as the representatives of the Council of the Royal Society on an Antarctic Executive Committee of four, Sir Clements Markham (Chairman) and Sir R. Vesey Hamilton being the representatives of the Royal Geographical Society's Council. Our functions were defined under various heads in a printed form previously agreed upon. No. 2 instructed us to submit a program of the Expedition for approval to the Joint Antarctic Committee (consisting of sixteen representatives of each Council), "such a programme to include (a) A general plan of the operations of the Expedition, including instructions to the Commander, so far as this can be laid down beforehand. (b) The composition of the executive and scientific staff to be employed, the duties, preparation and accommodation for, and pay of, the several members." No. 4 instructed us " to make the appointments of the several members of the executive and scientific staff, subject to the final approval of the Joint Committee." The word 'civilian' was nowhere employed. The four members of the Executive Committee were placed on the Joint Committee and all SubCommittees.

Before the first meeting of the Executive Committee, Captain Tizard and I were seen by Professor Rücker, who informed us that one of the first points which the Council of the Royal Society desired us to raise was the relation in power and status between the Commander and the Scientific Leader. In the German Expedition, which was to start about the same time, the Scientific Director had absolute power, and we were asked to consider the possibility of such an arrangement in the English Expedition.

At one of our first meetings, I think the very first, I raised this question and sup- ported the German arrangement. The other three members, who were all naval experts, convinced me that English law required the Captain to be supreme in all questions relating to the safety of his ship and crew. Since that time I have never disputed this point, but always maintained that the scientific chief should be head of the scientific work of all kinds, including the geographical, and that the Captain should be instructed to carry out his wishes, so far as they were consistent with the safety of ship and crew.

We then considered the appointment of Scientific Leader and decided to nominate Professor J. W. Gregory, then of the British Museum of Natural History. In suggesting his name to my colleagues, I was influenced by his proved success in organization and in the management of men in a most difficult expedition (British East Africa in 1893), by the wide grasp of science which enabled him to bring back valuable observations and collections in so many departments. His ice experience in Spitzbergen and Alpine regions was also of the highest importance, together with the fact that his chief subject was geology, a science which pursued in the Antarctic Continent would almost certainly yield results of especial significance. In addition to all these qualifications, Professor Gregory's wide and varied knowledge of the earth rendered his opinion as to the lines of work which would be most likely to lead to marked success extremely valuable in such an expedition. No one was more competent to state the probable structure of the Antarctic Continent and its relation to that of the earth. This opinion of Professor Gregory's qualifications for the position of scientific leader of an Antarctic expedition is, I know, widely held among British scientific men. In their wide combination, and united as they are to tried capacity as a leader, they are unique, and 
an expedition with Professor Gregory for its scientific chief, with as free a hand as English law would permit, was bound to yield great results.

The Committee deputed me to ask Professor Gregory if he would consent to be nominated. In doing soI carefully explained that he could not have the full powers of the German scientific leader. He consented to consider the offer favorably, but wished for a more definite statement of his position and powers, and for a program of the Expedition. Shortly after this he was appointed professor of geology at Melbourne, and left England. On the voyage he wrote a long letter to the Executive Committee (dated January 19, 1900), which he posted to me at Port Said. In it he said, "I have heard so many rumours as to what is wanted, that I cannot be sure whether I correctly understand the views and wishes of the Executive Committee: I therefore write mainly for the sake of correction, so that I may avoid any misstatements in communicating with the Council of Melbourne University, when the proposal from the Committee reaches me." The plan drafted by Professor Gregory in this letter included the provision of a landing party with house, observing huts, dog-stable, etc., and he argued that its organization should be placed ' in the hands of the scientific staff,' but that, under any circumstances, the Scientific Leader should have the opportunity of controlling a small independent party on land. This letter was read by all the members of the Executive Committee, and, on June 15th, at the close of the meet. ing, the Secretary despatched a cable to Professor Gregory containing the information "Your letter of January 19 has been received and approved." As soon as Professor Gregory received this he sent a decoded copy to Sir Clements Markham, who did not correct it. Indeed, at this period Sir Clements Markham frequently expressed opinions which implied that he contemplated the establishment of a landing party independent of the ship. Professor Gregory applied for and received from the Council of Melbourne University permission to take the appointment on the lines of his letter of January 19 th.

Professor Gregory's name was very warmly received by the Joint Committee and he was appointed Scientific Head on February 14, 1900 ; the words "Formally appointed, wire when fully able to decide," being cabled to him a few days later by Sir Clements Markham.

Lieutenant Robert F. Scott, Torpedo Lieutenant of H. M. S. Majestic, was appointed Commander of the Expedition by the Joint Committee, on May 25, 1900.

In June, 1900, my attention was called to a statement in the Press describing Professor Gregory as ' Head of the Civilian Scientific Staff.' Feeling confident that the word ' civilian' was not employed in the resolution accepted by the Joint Committee I wrote to Sir Clements Markham on the subject. In his absence the Secretary replied, "The words 'Head of the Civilian Scientific Staff' are the exact words of the resolution passed by the Joint Committee appointing Professor Gregory, and I know Sir Clements himself was very anxious to have the word 'civilian' in, so that no difficulty might arise between Professor Gregory and the Commander of the Expedition, since the civilians would not be the only scientific men on board." The word 'civilian' does certainly occur in the minutes of the meeting. On the other hand, Sir Clements Markham was not present on that occasion (February 14, 1900); the word 'civilian' did not occur in the instructions issued to the Executive Committee, and was not used in my letter to Sir Clements (February 15th) describing the result of the meeting and asking him to cable. 
The words I used, 'leader of Scientific Staff,' were not commented upon in his reply (February 16th), stating that the cable should be sent. The word 'civilian' was not used by Dr. W. E. Blanford, writing to convey the unanimous recommendation of the Geological Sub-Committee thatProfessor Gregory should be 'chief of the Scientific Staff of the Expedition.' Professor Herdman, who seconded the resolution on February 14th, and I, who proposed it, both remember the words 'Scientific Leader of the Expedition.' I have not been able to recover a copy of the cotice convening the meeting, in which the agenda were put down. It would, however, have been unreasonable for the Joint Committee to have accepted the word 'civilian' when it had no information before it which justified the expectation that naval officers would be lent by the Admiralty.

At the meeting of the British Association at Bradford, I explained the situation to Professor Rücker, who agreed with me that it was full of danger, on account of the reasons alleged for the use of the word ' civilian,' viz., in order to discriminate between the science under Professor Gregory and that under the Commander. He agreed with me that the coordination of all the science of the expedition ought to be in the hands of the scientific chief who had been selected, because his reputation was a guarantee that all interests would be properly looked after. Sir Michael Foster, to whom I mentioned the matter at a later date, quite agreed with this opinion, but was unwilling to contest the use of the term 'civilian.' Furthermore, when I raised the question at a meeting of the representatives of the Royal Society on the Joint Committee, it appeared that the term was actually preferred by certain influential naval authorities who were present, so that it was impossible to resist it without dividing those who desired to give Professor
Gregory such a measure of freedom of action as he was prepared to accept.

At the meeting (November 20, 1900) of the Joint Committee, following the conversations with Professor Rücker and Sir Michael Foster, a report from the Executive Committee and submission and estimate from Captain Scott were read and received, with certain modifications. I indicated to the Secretaries of the Royal Society, who were sitting opposite to me, that this was a favorable opportunity to raise the question of the powers of the Scientific Director over the whole of the science of the Expedition. They were, however, unwilling to do so, hoping, I believe, that all difficulties would be smoothed away by personal negotiations between Captain Scott and Professor Gregory, who was expected home in a fortnight.

For nearly two months these negotiations. proceeded between Professor Gregory on the one side and Captain Scott and Sir Clements. Markham on the other, and between Sir. Clements Markham and me.

The principles held were irreconcilable, and it only remained to appeal to the Joint. Committee for a decision.

On January 9, 1901, Professor Gregory wrote to Professor Rücker, explaining the failure of the negotiations, and on January 28th he addressed a letter to the Royal Society's representatives on the Joint Committee, from which I select the following paragraphs:

I landed at Liverpool on December 5, and went straight to Dundee to meet Captain Scott, and showed him a copy of my letter of January 19 [1900]. As he returned it to me next day without comment, I believed that he understood and accepted the general conditions therein stated. On January 7 , in order to. settle the exact terms of our mutual relations, I submitted to Captain Scott a draft of the instructions I expected to receive from the Joint Committee, and which I had previously shown to Professor Poulton. To my surprise Sir Clements Markham and Captain Scott expressed disapproval of these instructions, practically on the ground that there could be only 
one leader of the Expedition, and that that leader must be Captain scott.

My colleagues and myself were characterized as civilian scientific experts, accompanying the expedition to undertake investigations in those branches of science with which the ship's officers were unfamiliar, and it was proposed that, to maintain Captain Scott's complete control, all the scientific men should be required to sign articles.

According to this theory, the position of the scientific staff is accessory and subordinate. The contentions of Sir Clements Markham and Captain Scott would completely alter the position which I was invited to take and which alone I am prepared to accept. Were I to accompany the expedition on those terms there would be no guarantee to prevent the scientific work from being subordinated to naval adventure, an object admirable in itself, but not the one for which I understood this expedition to be organized.

The Executive Committee met on January 30 th and drafted instructions on lines approved by Sir Clements Markham. They were opposed by my colleague Captain Tizard, but in my absence through illness were passed by two votes to one.

A few days later the draft instructions were considered by the Royal Society's representatives, who appointed Sir Joseph Hooker, Sir William Wharton and Sir Archibald Geikie to suggest amendments. They carefully considered the draft and suggested several alterations, the most important of these being the instructions to the commander, (1) not to winter in the ice, (2) to establish between two named points on the coast a landing party with three year's stores, under the control of Professor Gregory.

The Royal Society's representatives again met and unanimously approved these amendments, which were submitted together with the draft instructions to the meeting of the Joint Committee on February 8th. The representatives of the Royal Geographical Society objected that they had not had the same opportunity of considering the instructions at a separate meeting, and that the amendments were sprung upon them. The meeting was accordingly ad- journed until February 12 th, the very day before Professor Gregory sailed. During the prolonged discussion which took place, the authorities on magnetism were unanimous in affirming that a station on land was essential in order to obtain the full value of the observations made on the ship.

Sir Clements Markham threatened that the Council of the R. G. S. would not accept the amended instructions, whereupon Sir Michael Foster drew attention to the letter which Sir Clements had written at the time when the Joint Committee was proposed.

The amendments were finally approved by 16 votes to 6 , and Sir Archibald Geikie and I were deputed to explain to Professor Gregory, who was in attendance, that he was to be landed in control of a small party, if a safe and suitable place could be found, and to ask if he would accept these conditions. We reported his consent to the meeting, which was then adjourned for the consideration of other details.

Two of the representatives of the R. G. S., Sir Anthony Hoskins and Sir Vesey Hamilton, resigned shortly afterwards, explaining that they could not agree with the action of the Committee. The R. G. S. had, however, the right, which it subsequently exercised, of appointing new members.

At the adjourned meeting, on February 19th, the question of the ship. wintering was discussed at length. Those who had practical experience of the Antarctic urged us strongly not to take the responsibility of permitting the ship to winter in the ice. Sir Joseph Hooker's statement of the danger was especially impressive, and the meeting decided in accordance with his opinion.

At the same meeting Major L. Darwin proposed to modify the conditions accepted by Professor Gregory, by adding to them the additional consideration that he should only be landed if the time of the ship should not be too greatly diverted from 
geographical exploration. I protested strongly against any modification at this stage. Sir Michael Foster opposed me; and, after the close of the meeting, there was a somewhat sharp though friendly expression of conflicting opinions, he maintaining that there should be 'give and take,' I that we were already pledged to Professor Gregory, that the arrangement was as it stood a compromise-the minimum Professor Gregory would accept-by no means the one which scientific men, not belonging to the navy, would have preferred.

At that meeting Major Darwin did not succeed, but his suggestion in somewhat different words was again brought forward at the next meeting on March 5th. Just before the meeting Sir Archibald Geikie told me that he intended to support the proposed changes ' in the interests of peace,' and that Mr. Teall, and Mr. George Murray, Professor Gregory's representative, also approved them. Resistance was hopeless ; I could only protest against any alteration of the conditions offered and accepted, requesting that my name and the names of those who agreed with me (Mr. J. Y. Buchanan and Captain Tizard) should be recorded.

I wrote to Professor Gregory a full account of what had happened, carefully explaining that his representative and many of his friends supported the changes, that I had confidence that the proposal was made to enable the Geographical Society to accept the instructions and that it was not intended to prevent, and, I believed, would not prevent, his being landed.

In spite of the incorporation of Major Darwin's changes the R. G. S. Council refused to accept the instructions, but addressed a letter signed by their President, dated March 18th, to the members of the Joint Committee stating that they were compelled, "as trustees for the money subscribed through their society and for the funds voted by their Society, to regard the above scientific objects [viz., those to be carried out by a landing party] as subsidiary to the two primary objects of the Expeditionnamely, exploration and magnetic observations." In view of the unanimous witness of all experts that the landing party was essential for full success in the magnetic work this statement is sufficiently remarkable.

The letter went on to inform us that the President, Sir Leopold McClintock, and Sir George Goldie had interviewed the officers of the Royal Society and had reported to the R. G. S. Council which now suggested that the Joint Committee should recommend a small committee of six, three to be appointed by each Council, to deal finally with the instructions. The Council of the R. G. S. agreed to accept the decision of this committee provided the Council of the Royal Society agreed to do the same.

It has been stated in various directions that the Geographical Society produced new evidence (based upon the experience of Borchgrevink and the intentions of the German leader) which had not been laid before the Joint Committee, and thus induced the officers of the Royal Society to agree to a new committee. To this it may be replied that these sources of information had been open to the Joint Committee, and that, if anything new had arisen, it was reasonable to refer it to the old committee rather than to a new one appointed ad hoc. Furthermore, the letter of the Royal Geographical Society, referred to above, clearly indicated that the real intention was to escape from the conditions proposed to and accepted by the Scientific Leader.

The Joint Committee met on April 26th, and was addressed in favor of the course proposed by the R. G. S. Council by Sir George Goldie. Nothing was said which could diminish the conviction that the R. G. S. Council and that of the R. S. in weakly 
consenting to nominate a fresh committee had struck a disastrous blow at all future cooperation between scientific bodies in this country.

What reply could the officers make if they were asked to advise the Council of the Royal Society to cooperate with that of the Royal Geographical Society on any future occasion?

I felt justified in asking what guarantee was there that the Council of the Royal Geographical Society would accept the finding of the committee of six, when it had refused to accept that of a committee which included all the officers and almost every expert in Arctic and Antarctic exploration from both societies. In reply Sir Michael Foster, in spite of the promise of firmness held out by his attitude on February 12th, when Sir Clements Markham threatened that his council would repudiate the finding of the Joint' Committee, maintained that they had only acted within their rights, and that the Royal Society Council claimed the right to do the same if it had not agreed with the decision.

At this point it will be convenient to give a list of the representatives of the Royal Society on the Joint Antarctic Committee, the representatives of the Royal Geographical Society being equally significant in relation to the council of their own society. They are the President, the Treasurer, the Senior Secretary, the Junior Secretary, Mr. A. Buchan, Mr. J. Y. Buchanan, Captain Creak, Sir J. Evans, Sir A. Geikie, Professor Herdman, Sir J. D. Hooker, Professor Poulton, Mr. P. L. Sclater, Mr. J. J. H. Teall, Captain Tizard, and Admiral Sir W. J. L. Wharton.

If the reports of Joint Committees of such magnitude and weight are to be thrown over with the approval of the councils of both societies because a majority of one council does not agree with the conclusions, men will rightly hesitate before consenting to devote an immense amount of time and trouble to the work of the Society, and the efficiency of the Royal Society will be greatly diminished.

The considerations set forth above indicate the future injuries which are likely to be inflicted on our Society by this surrender. At the meeting on April 26th, I was more concerned with the immediate and pressing injury, and therefore urged that the Royal Society was a trustee for the interests of science and that we had pledged ourselves to secure certain powers to the Scientific Director, that it was better the expedition should not start (a contingency contemplated as possible by Sir George Goldie, but not a serious danger, I believe, even though the Royal Society had stood firm and appealed to the Government, not on the subject-matter in dispute, but on the refusal of the Royal Geographical Society to work with the recognized methods of cooperation) than that the Royal Society should betray its trust, that the fellows of the Society would not support the officers in thus yielding to the Royal Geographical Society, and that I should feel bound to explain my position to the Society. Sir Archibald Geikie and Mr. J. Y. Buchanan also strongly objected to the surrender, which was then confirmed by a large majority of those present.

We were told by Sir George Goldie that the three representatives of the Royal Geographical Society on the new committee would be Sir Leopold McClintock, Mr. Mackenzie, and Sir George himself ; by Sir Michael Foster that the Royal Society Council would appoint three non-experts, viz.: Lord Lister, Lord Lindley and the Treasurer, who could pronounce without bias upon the whole of the evidence. My colleague, Captain Tizard, with whom I had worked with the most complete sympathy and agreement through the whole course of the negotiations, supported the 
formation of the new committee, because of Sir Michael's assurance that all evidence would be sifted and because of his faith in the validity of the evidence he had to give. Others probably voted in the affirmative for the same reason.

Without asking for evidence from Sir Joseph Hooker, Sir W. Wharton, Sir George Nares, Sir A. Geikie, Captain Creak, Captain Tizard or Mr. Buchanan, the new committee proceeded to cable to Melbourne the modifications which have led Professor Gregory to resign.

In bringing a condensed account of the negotiations before the Fellows of the Royal Society I desire to call attention to certain special difficulties which the Society has had to encounter in the struggle.

(1) The fact that nearly the whole of the money voluntarily subscribed was obtained through members of the Geographical Society and from its funds.

(2) The fact that Sir Clements Markham, President of the Royal Geographical Society, a man of remarkable energy, resource and resolution, was the chief antagonist of the amendments passed by the Joint Committee.

(3) The fact that the Junior Secretary and Sir John Evans were absent from England during the most critical period.

(4) Professor Gregory's appointment to the Chair at Melbourne, involving his absence from England during a large part of the negotiations.

Making all allowance for these difficulties, I believe that the majority of the fellows will consider that the claims of the scientific chief in an expedition undertaken to do scientlfic work have not received from the Royal Society that unflinching, undivided and resolute support which they would have expected and desired.

Edward B. Poulton.

OXFORD, May 15, 1901.

FIRST REPORT OF THE LIMNOLOGICAL COMMISSION OF THE AMERICAN MICROSCOPICAL SOCIETY.

The initial report of a body so recently organized as this can hardly be more than preliminary in character, all the more so that the field entrusted to it is as extensive as untried. When, by the action of this Society a yearago, the Limnological Commission was organized and its members asked to assume the duties laid upon them in connection therewith, they accepted, not without some hesitancy at the extent of the work before them. The study of fresh-water bodies is indeed a great field, barely touched upon at one or two points in this country, and nowhere in the world even superficially covered as yet. Nevertheless it was the original field of biologic study ; it was and is accessible to public and private workers practically everywhere, and affords opportunities for extended or limited work in any particular department of biologic research towards which the student may be drawn. Furthermore, to this work attaches an undoubted interest for all who come within its territory, while its problems have not only great biologic importance, but are also of economic value as well as of decidedly practical character, touching as they do upon the important questions connected with fish culture, municipal water supply and sewage disposal.

In this first report it will not be possible to do more than outline succinctly what has developed from our correspondence and discussion thus far regarding the object of the work, to make a brief survey of the field under discussion, of the ends to be reached and of some of the means for attaining them, and finally to invite propositions concerning the methods and problems under consideration and cooperation in proceeding toward their solution.

It may be fitting at the outset to state briefly the outlook before the Commission. Such a venture as this is not entirely unheard of and consequently venturesome. A similar body was appointed some years ago by the Swiss National Society of Natural Sciences. As a Swiss investigator, 